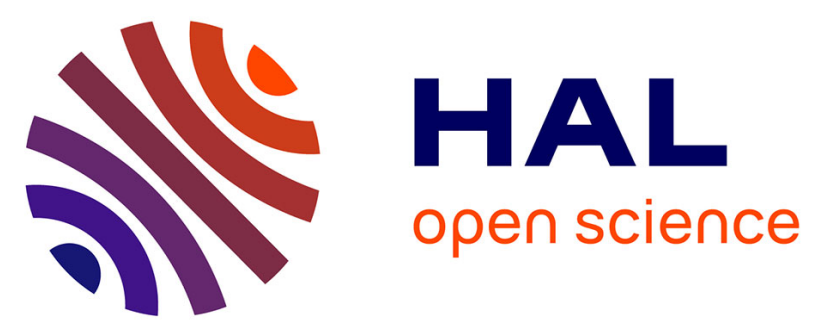

\title{
Selective carbon deposition on $\gamma$-alumina acid sites: towards the de- sign of catalyst supports with improved hydrothermal stability in aqueous media
}

Etienne Girel, Amandine Cabiac, Alexandra Chaumonnot, Michèle Besson, Alain Tuel

\section{To cite this version:}

Etienne Girel, Amandine Cabiac, Alexandra Chaumonnot, Michèle Besson, Alain Tuel. Selective carbon deposition on $\gamma$-alumina acid sites: towards the de- sign of catalyst supports with improved hydrothermal stability in aqueous media. ACS Applied Materials \& Interfaces, 2020, 12 (11), pp.1355813567. 10.1021/acsami.0c01646 . hal-02553402

\section{HAL Id: hal-02553402 \\ https://hal-ifp.archives-ouvertes.fr/hal-02553402}

Submitted on 5 May 2020

HAL is a multi-disciplinary open access archive for the deposit and dissemination of scientific research documents, whether they are published or not. The documents may come from teaching and research institutions in France or abroad, or from public or private research centers.
L'archive ouverte pluridisciplinaire HAL, est destinée au dépôt et à la diffusion de documents scientifiques de niveau recherche, publiés ou non, émanant des établissements d'enseignement et de recherche français ou étrangers, des laboratoires publics ou privés. 


\title{
Selective carbon deposition on $\gamma$-alumina acid sites: towards the de- sign of catalyst supports with improved hydrothermal stability in aqueous media
}

\author{
Etienne Girel ${ }^{1,2}$, Amandine Cabiac ${ }^{1}$, Alexandra Chaumonnot ${ }^{1}$, Michele Besson $^{2}$, Alain Tuel $^{2 *}$ \\ 1Direction Catalyse et Séparation, IFP Energies nouvelles, Rond-point de l'échangeur de Solaize, BP 3, 69360 Solaize, \\ France \\ 2Université de Lyon, Université Claude Bernard Lyon 1, CNRS, IRCELYON - UMR 5256, 2 Avenue Albert Einstein, \\ 69626 Villeurbanne Cedex, France
}

KEYWORDS $\gamma$-alumina boehmite transformation; hydrothermal decomposition; sorbitol; adsorption; pyrolysis; carbon.

\begin{abstract}
: $\gamma$-alumina, a widely used industrial catalyst support, undergoes irreversible transformation into various aluminum hydroxides under hydrothermal conditions, resulting in strong modification of its intrinsic properties. Most of the strategies that have been proposed to prevent or at least minimize its transformation into oxy-hydroxides consist in covering the alumina surface by a hydrophobic carbon layer, making it less sensitive to modifications induced by water. However, such methods necessitate high carbon contents, which significantly modifies structural and chemical properties of alumina. Here, we propose a new method based on a series of adsorption/pyrolysis cycles using sorbitol molecules previously adsorbed on specific hydration sites of (110) faces of $\gamma$-alumina crystals. Those sites, which are responsible for the dissolution of $\gamma$-alumina crystals in water, are thus selectively protected by carbon clusters, the rest of the surface being totally exposed and accessible to adsorbates. Under hydrothermal conditions (10 hours in water at $200^{\circ} \mathrm{C}$ ), the formation of hydroxides is almost totally suppressed by covering less than $25 \%$ of the surface with only 7 wt. \% carbon, which is far below the amount necessary to get similar results with more conventional carbon deposition methods.
\end{abstract}

\section{- INTRODUCTION}

Molecules derived from existing biomass treatment processes such as fermentation and hydrolysis (sugars, alcohols, polyols, carboxylic acids, etc.) are platform molecules for bio-based products manufacture. They consist of oxygen-rich, highly functionalized and generally water soluble molecules and reactions to convert them into valuable bio-products in aqueous media may require relatively high temperatures and sometimes high pressures. These particular conditions, which combine water and temperature, are called hydrothermal conditions (HT) and they represent a serious challenge in the field of today's heterogeneous catalysis. ${ }^{1,2}$ Indeed, conventional catalysts used in the petroleum refining industry generally consist of an active metal phase deposited onto an inorganic support and they may not be appropriate for applications involving water as solvent under such HT conditions. For example, $\gamma$-alumina, a widely used industrial catalyst support, undergoes irreversible transformation into various aluminum hydroxides by a dissolution/re-precipitation process when placed in a water-rich medium at moderate temperature, resulting in strong modification of its intrinsic properties. ${ }^{3,4,5-8}$ The stability of alumina materials in water has been a matter of great interest during the last years and many strategies have been proposed to prevent or at least minimize their transformation into hydroxides. The approach generally consists in modifying the alumina surface in order to make it less sensitive to the modifications produced by water under hydrothermal conditions. The benefits of organic additives (such as carbon $^{9,10}$ ), inorganic additives (such as silicon ${ }^{11,12}$ or phosphorus $^{13}$ ) and metallic additives ${ }^{14}$ on the HT stability of alumina have been reported. However, the main parameters that govern the dissolution of alumina remain poorly known, which makes difficult the development of rational methods to improve the stability of this material. Ravenelle and coworkers first noticed that alumina transformation did not occur when polyols were present in the aqueous medium during a hydrothermal process. ${ }^{15,16}$ The effect is supposed to result from the chemisorption of the organic molecules on alumina, which avoids direct contact between water molecules and the surface and significantly improves water resistance. ${ }^{17}$ This result can be compared with the work of Pham et al. who increased alumina stability in water by covering its surface with an oxygenated carbonaceous layer resulting from sucrose pyrolysis at $400^{\circ} \mathrm{C}$. They showed that $10 \mathrm{wt}$. \% of carbonaceous deposit on the alumina surface was enough to prevent the transformation of the solid into boehmite. In another study, the same group used methane as a carbon source to produce graphitic carbon on alumina surface by gas phase carbonization. In this case, a higher amount of carbon was required to effectively protect alumina (35 wt. \%), leading to a complete modification of its original properties (textural properties and surface chemistry). ${ }^{10}$ Despite a growing number of articles dedicated to the improvement of alumina based materials in hydrothermal conditions, rationalization of predominant parameters that control hydrothermal stability remain unclear. In a previous work, we proposed a mechanism of the first steps of alumina dissolution based on experimental and theoretical approaches. ${ }^{18}$ This mechanism involves some specific surface sites located on basal (110) planes of alumina platelets which are particularly reactive towards liquid water. We also showed 
that sorbitol and xylitol preferentially adsorb on these specific sites of the alumina surface, which explains the effect observed by Ravenelle and al. when alumina was treated in the presence of polyols in solution. ${ }^{15,16}$

Herein, we propose an original approach to synthesize $\mathrm{C} / \gamma$ alumina composites using adsorbed polyol molecules as carbon source. The synthesis route makes it possible to control and optimize some of the critical parameters that affect the transformation of alumina in water. We discuss the importance of carbon surface coverage and its localization on the alumina surface on the stability of the solid. The advantages of this new synthesis route are demonstrated by comparing the obtained composites with those obtained using more conventional methods of the literature. As a proof of concept, this preliminary work mainly concerns the stability of the support, which is the basement for the preparation of stable supported catalysts.

\section{- EXPERIMENTAL SECTION}

\section{Material synthesis}

$\gamma$-alumina was obtained by calcination under air of a commercial boehmite (Sasol PURAL SB) at $600^{\circ} \mathrm{C}$ for $4 \mathrm{~h}$ with a heating rate of $5^{\circ} \mathrm{C} / \mathrm{min}$.

Carbon/ $\gamma$-alumina composites were synthesized using 3 different methods: incipient wetness impregnation/pyrolysis of sucrose or sorbitol, chemical vapor deposition of ethanol and adsorption/pyrolysis of sorbitol.

Incipient wetness impregnation: materials were synthesized following the protocol described by Lin and al. ${ }^{19}$ An aqueous solution of sucrose or sorbitol with various concentrations was impregnated on $2 \mathrm{~g}$ of alumina powder, the material was dried at ambient temperature overnight and heated at $400^{\circ} \mathrm{C}$ or $600^{\circ} \mathrm{C}$ under nitrogen for $1 \mathrm{~h}$ with a $5^{\circ} \mathrm{C} / \mathrm{min}$ heating rate.

CVD of ethanol: $8 \mathrm{~g}$ of alumina powder were placed in a tubular reactor equipped with an ethanol saturator. After 15 min at $600^{\circ} \mathrm{C}$ under pure nitrogen flux $(50 \mathrm{~mL} / \mathrm{min})$, the gas flow was passed through the ethanol saturator maintained at $30^{\circ} \mathrm{C}$ (see scheme in ESI). After a given reaction time, the reactor was cooled down under nitrogen and the solid was recovered.

Adsorption/pyrolysis: $15 \mathrm{~g}$ of alumina were dispersed in 100 $\mathrm{mL}$ of an aqueous solution of sorbitol $(75 \mathrm{~g} / \mathrm{L})$. After $2 \mathrm{~h}$ at $200^{\circ} \mathrm{C}$ under autogenous pressure (14 bar) and vigorous stirring, the autoclave was cooled at room temperature and the solid phase was recovered by centrifugation, dried in an oven at $100^{\circ} \mathrm{C}$ overnight and heated at $600^{\circ} \mathrm{C}$ under nitrogen for $1 \mathrm{~h}$ with a $5^{\circ} \mathrm{C} / \mathrm{min}$ heating rate. This process was then repeated using the same material, sorbitol concentration was adjusted with the mass of material treated (see main text for details).

Hydrothermal test. The hydrothermal stability of the different materials was evaluated through an on purpose hydrothermal stability test. Typically, $2 \mathrm{~g}$ of $\gamma$-alumina were dispersed in 50 $\mathrm{mL}$ of deionized water. The mixture was heated at $200^{\circ} \mathrm{C}$ for $10 \mathrm{~h}$ under mechanical stirring and autogenous pressure in a $100 \mathrm{~mL}$ stainless steel autoclave. After cooling at ambient temperature, the powder was recovered by centrifugation and dried à $100^{\circ} \mathrm{C}$ overnight. The same procedure was adopted for the sorbitol adsorption experiments except that aqueous solutions of sorbitol with different concentrations were used in- stead of pure water. In this case, the liquid phase was systematically analyzed after each treatment to determine the final sorbitol concentration.

Solution Analysis. Sorbitol concentrations were determined by HPLC analysis using a Shimadzu LC20A instrument connected to a differential refraction detector (Shimadzu RID10A) and equipped with a Rezex RXM-Monosaccharide $\mathrm{Ca} 2+8 \%$ column $\left(7.8 \mathrm{~mm} \times 300 \mathrm{~mm}\right.$ heated at $\left.60^{\circ} \mathrm{C}\right)$. The amount of polyol adsorbed on the alumina surface was calculated by the difference between initial and final concentrations and was expressed per mass of $\gamma$-alumina ( $\%$ polyol adsorbed $=$ mpolyol adsorbed/malumina $* 100$ ).

\section{Characterization techniques}

Powder X-ray diffraction (XRD) analyses were performed using a Bragg Brentano diffractometer (PANalytical X'Pert PRO MDP) using $\mathrm{Cu} \mathrm{K} \alpha$ radiation. Diffractogrammes were obtained within the $4-74^{\circ} 2 \theta$ range with a step of $0.033^{\circ}$ and 5 $\mathrm{s}$ per step. The fraction of boehmite phase in a solid was estimated by integrating the peak at $14.5^{\circ}$ corresponding to the (020) reflection of $\mathrm{AlOOH}$ in the corresponding XRD pattern. A calibration curve was first done using $\gamma$-alumina/boehmite mechanical mixtures (See Figure S1, ESI). The AlOOH phase used for calibration was obtained by HT treatment of $\gamma$ alumina for $10 \mathrm{~h}$ at $200^{\circ} \mathrm{C}$. All solids were tested just after drying at $100^{\circ} \mathrm{C}$ overnight.

Textural properties of materials were determined by $\mathrm{N}_{2}$ sorption studies at $-196^{\circ} \mathrm{C}$ using a Micromeritics ASAP 2000 instrument. The BET method was applied to determine the specific surface area. Prior to the analysis, samples were dried at $150^{\circ} \mathrm{C}$ for $6 \mathrm{~h}$ under primary vacuum.

Transmission electron microscopy (TEM) images were obtained on a JEOL 2010 LaB6 microscope operating at $200 \mathrm{kV}$. A dispersion of the sample crushed in ethanol was deposited on standard holey carbon-covered copper TEM grids.

The nature of the carbon deposits in sorbitol $/ \gamma$-alumina materials was studied by ${ }^{13} \mathrm{C}$ solid-state nuclear magnetic resonance (NMR) on an Avance II 500 WB spectrometer (B0 magnetic field of 11,7 T). Magic angle spinning (MAS) spectra were recorded at $10 \mathrm{kHz}$ using a single pulse sequence with 60 s recycle delay. ${ }^{1} \mathrm{H}-{ }^{13} \mathrm{C} \mathrm{CP} / \mathrm{MAS}$ spectra were acquired at the same spinning speed using a classical cross-polarization (CP) technique with $2 \mathrm{~ms}$ contact time and $10 \mathrm{~s}$ delay.

TGA analyses were performed using a Mettler TGA851 thermobalance. The carbon content was calculated by integration of the mass loss between 200 and $750^{\circ} \mathrm{C}$ corrected with the mass loss of pure $\gamma$-alumina (see Figures S2 and S3, ESI).

Raman spectra were acquired on a Renishaw spectrometer equipped with a laser emitting a $532 \mathrm{~nm}$.

The proportion of surface covered with carbon in $\mathrm{C} / \gamma$ alumina composites was estimated by ethanol (EtOH) adsorption followed by TGA analysis. This characterization method was adapted from the work of Caillot and $\mathrm{al}^{20}$ and of Kwak and $\mathrm{al}^{21}$ The amount of EtOH that remains adsorbed on the composite after surface saturation followed by desorption under inert atmosphere corresponds to $\mathrm{EtOH}$ on free alumina since the interaction of the alcohol with carbon is very weak. In contrast, alumina surface strongly adsorbs EtOH and most of the molecules adsorbed cannot desorb under a simple flow of inert gas without increasing temperature (Figure S4, ESI). 


\section{- RESULTS AND DISCUSSION}

Stability of $\gamma$-alumina in water. The kinetics of $\gamma$-alumina transformation under hydrothermal conditions was first investigated. Figure 1 shows the percentage of $\mathrm{AlOOH}$ at $200^{\circ} \mathrm{C}$ for different periods, estimated from the corresponding XRD patterns using the relationship plotted in Figure S1 (see ESI). The transformation was complete after $90 \mathrm{~min}$, which is considerably less than the duration reported by Ravenelle et al. ${ }^{22}$ $(10 \mathrm{~h})$ but in agreement with a more recent work of the same team $^{13}$ (Figure S5, ESI).

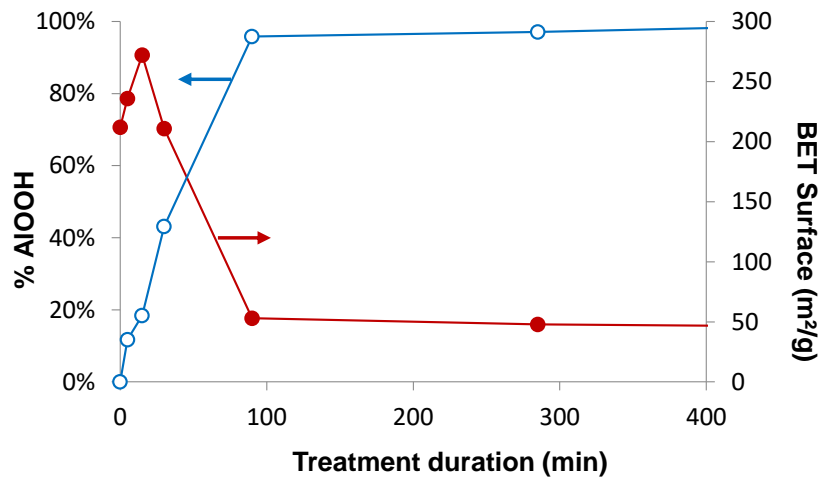

Figure 1 Percentage of $\mathrm{AlOOH}$ formed (left axis) and specific surface area (right axis) of $\gamma$-alumina after HT treatments at $200^{\circ} \mathrm{C}$ in water for different periods

This difference may result from the different nature of the initial $\gamma$-alumina material and from the conditions used for the treatment (volume of the autoclave, stirring speed ...). Indeed, Abi Aad et al. have shown that the kinetics of alumina dissolution depends on its specific surface area and crystal structure (allotropic form). ${ }^{3}$ Despite those differences, the duration of the HT treatment was kept at $10 \mathrm{~h}$, which is long enough to estimate the stability of pure and modified alumina materials.

The specific surface area was much affected by the HT treatment: it first increased from 212 to $272 \mathrm{~m}^{2} / \mathrm{g}$ during the first 15 minutes and then drastically decreased to $45 \mathrm{~m}^{2} / \mathrm{g}$ (Figure 1). These observations are once again in good agreement with previous works. ${ }^{5,1}$ The initial evolution has been attributed to an increase of the roughness of the alumina surface due to the formation of $\mathrm{AlOOH}$ micro domains. As these micro domains grow, the morphology of the particles changes as it can be observed on TEM pictures (Figure 2) and the surface area continuously decreases. While fresh $\gamma$-alumina is composed of aggregated nano platelets with an average size of $8 \mathrm{~nm}, \mathrm{AlOOH}$ crystallites are much larger and they can reach several hundreds of nanometers. This modification in size and morphology corresponds to the textural modifications discussed before, in particular the evolution of the BET surface area. The same phenomena were also observed by Jun Cheng and al. using MEB analysis. ${ }^{23}$ Unlike the boehmite $\rightarrow$ alumina transition upon calcination, the $\gamma$-alumina $\rightarrow$ boehmite transformation is not topotactic, i.e. the crystal lattice of boehmite does not show any relationships to the crystal lattice of $\gamma$ alumina. $^{26,27}$ The mechanism of this transformation has already been discussed by Carrier and al. ${ }^{4}$ and Abi Aad et al. ${ }^{3,11}$ It was proposed to be a dissolution/recrystallization process, which is in good agreement with our observations.

Other textural properties were also modified during the HT treatment. The shape of hysteresis loops in $\mathrm{N}_{2}$ sorption isotherms changed, revealing a deep modification of the porous structure, in particular the $\mathrm{BJH}$ pore diameter distribution (Figure S6, ESI). The porous volume decreased from 0.55 to $0.32 \mathrm{~mL} / \mathrm{g}$ and the mesopore population with a mean diameter around $8 \mathrm{~nm}$ vanished.

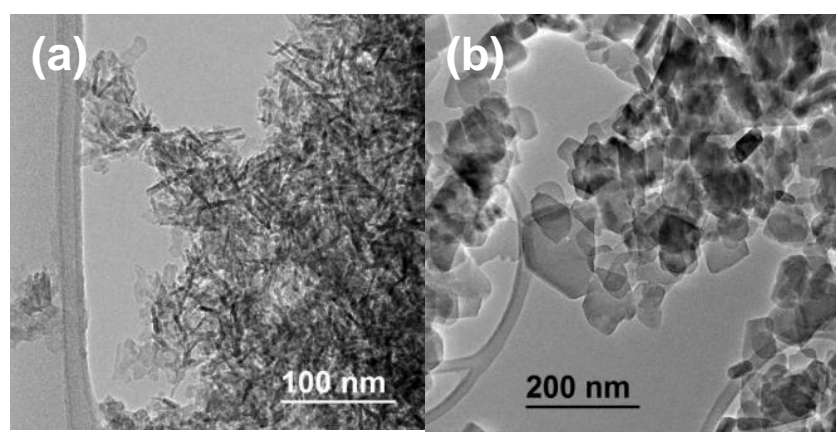

Figure 2 TEM pictures of $\gamma$-alumina before (a) and after (b) a 10 hour HT treatment at $200^{\circ} \mathrm{C}$ in water

Stability of $\boldsymbol{\gamma}$-alumina in the presence of sorbitol. Ravenelle and al. have shown that the presence of sorbitol in the HT solution resulted in the prevention of the transformation of $\gamma$ alumina into boehmite ${ }^{15}$. They attributed it to a strong multidentate and irreversible adsorption of the polyol, creating a protective organic layer on the alumina surface. In our work, $\gamma$-alumina was first treated with a solution of sorbitol $(25 \mathrm{~g} / \mathrm{L})$, then recovered by centrifugation and dried. As expected, the corresponding XRD pattern was characteristic of a pure $\gamma$ alumina material, thus confirming the protective role of sorbitol molecules (Figure 3). The solid was then submitted to a second hydrothermal treatment in pure water. Weak additional peaks corresponding to traces of $\mathrm{AlOOH}$ were observed by XRD suggesting a very strong sorbitol $/ \gamma$-alumina interaction since a part of sorbitol adsorbed was not removed from the surface even when no molecule was present in solution.

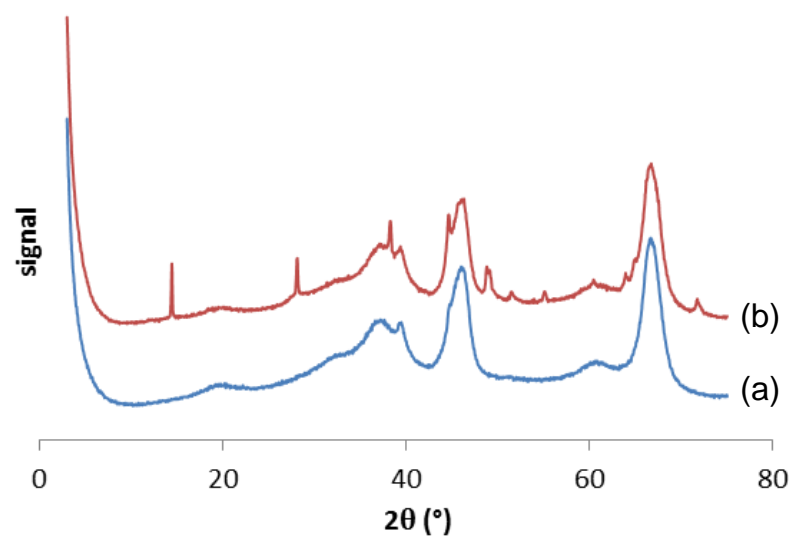

Figure 3 XRD patterns of (a) alumina after a HT treatment $\left(10 \mathrm{~h} ; 200^{\circ} \mathrm{C}\right)$ in a $25 \mathrm{~g} / \mathrm{L}$ aqueous solution of sorbitol and (b) the same solid after a second conventional HT treatment in pure water 
However, the appearance of a small fraction of boehmite indicates that adsorption was not fully irreversible and that the material would likely become less and less stable upon multiple HT treatment in pure water. After any HT treatments in the presence of sorbitol, sorbitol was the only product detected in the liquid phase, indicating that the molecule remained intact and did not transform at $200^{\circ} \mathrm{C}$. This was confirmed by ${ }^{13} \mathrm{C}$ solid-state NMR: the spectrum of the solid after sorbitol adsorption showed two bands at ca. 64 and 73 ppm with an intensity ratio of 1:2 (Figure S7, ESI). ${ }^{26}$ Chemical shifts and relative intensities are the same as those observed for sorbitol, indicating that the molecule retains its molecular structure upon adsorption. ${ }^{26}$ The relatively broad signals indicate that sorbitol molecules are immobilized on the surface of alumina with a reduced mobility.

The minimum sorbitol concentration necessary to stabilize $\gamma$ alumina was estimated by performing a series of HT treatments in solutions with concentrations in the range of $0.25-15$ $\mathrm{g} / \mathrm{L}$. The amount of boehmite formed decreased as polyol concentration increased and a total stability of the alumina was obtained for concentrations between 2 and $4 \mathrm{~g} / \mathrm{L}$ (Figure S8, ESI). ${ }^{18}$

The amount of sorbitol adsorbed on the solid (determined by HPLC analysis of the equilibrated solution) first increased rapidly with the concentration to reach about $2 \mathrm{wt}$. \% at $\mathrm{C}=2$ $\mathrm{g} / \mathrm{L}$ (Figure 4). In this region, there is a direct correlation between the amount of sorbitol adsorbed and the amount of AlOOH formed. Above $2 \mathrm{~g} / \mathrm{L}$, the amount of sorbitol adsorbed increased more slowly to reach $3 \mathrm{wt}$. $\%$ at $\mathrm{C}=15 \mathrm{~g} / \mathrm{L}$. This suggests that primary adsorption sites become saturated at concentrations between 2 and $4 \mathrm{~g} / \mathrm{L}$ and that sorbitol adsorbed at higher concentrations is no more necessary to fully protect alumina from dissolution.

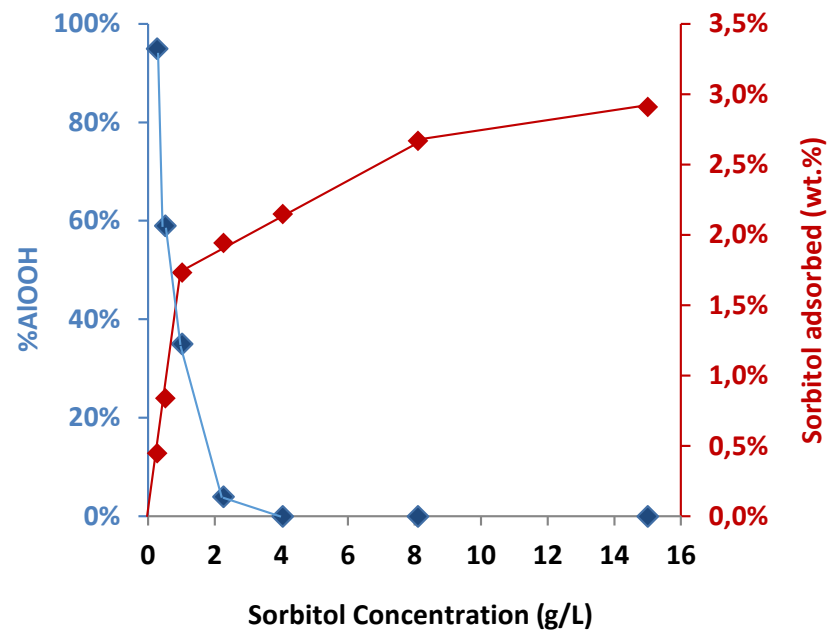

Figure 4 Evolution of the proportion of $\mathrm{AlOOH}$ and of the amount of sorbitol adsorbed after $10 \mathrm{~h}$ HT treatments at $200^{\circ} \mathrm{C}$ in aqueous solutions of sorbitol with different concentrations

Assuming that sorbitol molecules adsorb in their linear conformation with $\mathrm{OH}$ groups in threo configuration directed towards the alumina surface, the projected surface area of one molecule is estimated to $60 \mathrm{~A}^{2}$ (calculated with Molecular Shadow software using the methodology developed by Rohbaurd and al). ${ }^{27} \mathrm{~A}$ concentration of $2 \mathrm{wt}$. \% of sorbitol adsorbed (at $\mathrm{C}=4 \mathrm{~g} / \mathrm{L}$ ) corresponds to a density of 0.33 sorbitol $/ \mathrm{nm}^{2}$ and a coverage of about $20 \%$ of the total surface of $\gamma$ alumina crystals. Since boehmite is not formed under such conditions, it seems that the surface does not require to be fully covered with sorbitol to efficiently protect alumina from dissolution. This suggests that sorbitol adsorbs preferentially on specific adsorption sites, which are those whence dissolution process starts. Identification and description of those specific adsorption sites have been discussed in our previous work. ${ }^{18} \mathrm{We}$ showed that polyols adsorb on two neighboring octahedral aluminum atoms localized on (110) basal surface planes of alumina platelets, in good agreement with the work of Copeland and al. regarding glycerol adsorption. ${ }^{28}$ This result can be compared with the work of Watling and al. who discussed the adsorption of polyols on gibbsite crystals and suggested a selective adsorption on specific surface sites. ${ }^{29}$

New design of C/alumina materials. Although sorbitol $/ \gamma$ alumina composites are stable under HT conditions, they cannot be used as catalyst supports for long-term reactions, in particular if sorbitol is absent from the reaction medium (Figure 3 ). In addition, sorbitol $/ \gamma$-alumina cannot withstand high temperature treatments (calcination or pyrolysis) because of polyol thermal degradation. To overcome those limitations, we attempted to synthesize a carbon $/ \gamma$-alumina composite by pyrolysis of polyol molecules selectively adsorbed on sites of $\gamma$-alumina involved in dissolution mechanism. Assuming that carbon is formed locally where polyol molecules are adsorbed, the thermal treatment (pyrolysis) would lead to a composite in which carbon is located on - or at least close to - the hydration sites. Thus, we expected to produce a material with carbon deposited specifically on alumina primary hydration sites.

The $\mathrm{C} / \gamma$-alumina composite, obtained by pyrolysis at $600^{\circ} \mathrm{C}$ of a sample prepared by adsorption of sorbitol using a highly concentrated solution $(75 \mathrm{~g} / \mathrm{L})$ contained $1.5 \mathrm{wt}$. \% C, showed very low hydrothermal stability under HT conditions with more than $95 \%$ of boehmite formed after the treatment. The pyrolysis process is accompanied with the release of oxygen atoms (mostly as $\mathrm{H}_{2} \mathrm{O}$ molecules). Carbon formation certainly involves condensation of several sorbitol molecules, so the surface occupied by the resulting pyrolytic carbon cannot be as high as the one occupied by sorbitol. As a consequence, some of the adsorption sites that were protected by sorbitol molecules become exposed again after the pyrolysis treatment and the resulting material shows a poor stability. The amount of carbon, and therefore its surface coverage, was increased by repeating the adsorption/pyrolysis process several times on the same material. Between two consecutive cycles, the experimental process was adapted to keep the sorbitol/alumina ratio constant and particular attention was paid to saturate all adsorption sites after each process by keeping sorbitol concentration higher than the minimal required for a full protection of alumina.

TGA derivative curves of sorbitol/alumina composites obtained from a series of successive cycles before and after pyrolysis show two major weight losses: a first one between 200 and $400{ }^{\circ} \mathrm{C}$ corresponding to the degradation of adsorbed sorbitol into $\mathrm{CO}_{2}+\mathrm{H}_{2} \mathrm{O}$ and a second one between 400 and $550^{\circ} \mathrm{C}$ attributed to the combustion of carbon formed upon pyrolysis (Figure 5).

The amount of carbon formed increases with the number of cycles as one of adsorbed sorbitol decreased. 


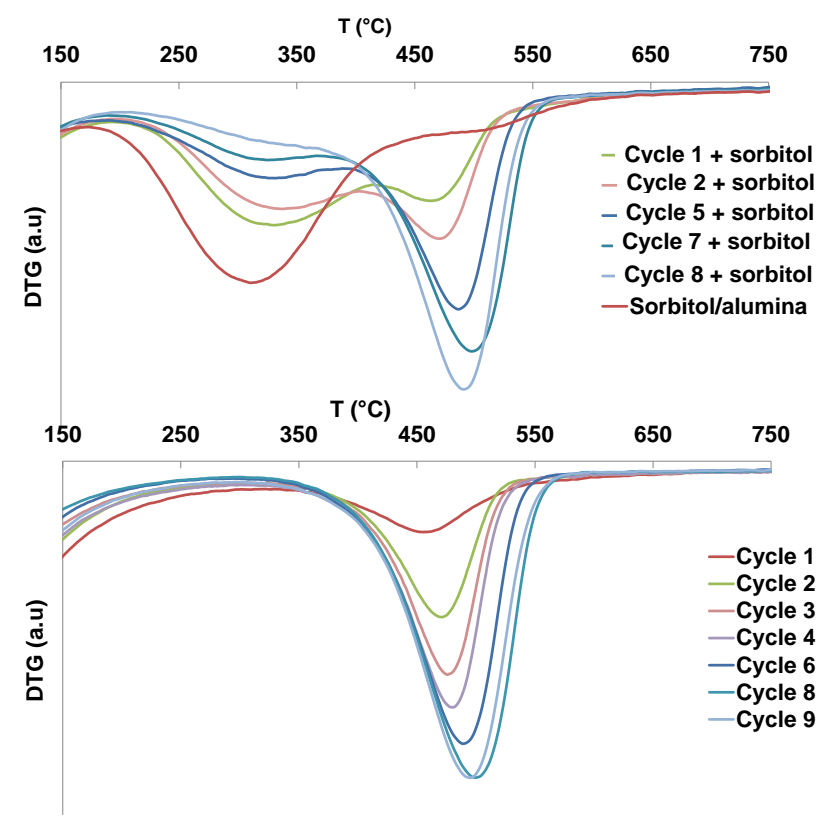

Figure 5 TGA derivative curves of sorbitol $/ \gamma$-alumina materials prepared by adsorption/pyrolysis cycles before (top) and after (bottom) the pyrolysis step. Conditions: air $25 \mathrm{~mL} / \mathrm{min}$, temperature ramp: $10^{\circ} \mathrm{C} / \mathrm{min}$ )

After 7 adsorption/pyrolysis cycles, the amount of carbon formed became high enough to completely prevent sorbitol adsorption (figure 5, cycle 8) and the carbon content no longer increased (Figure 6). This solid showed a very low sorbitol adsorption capacity, indicating that most of the adsorption sites had been covered with carbon.

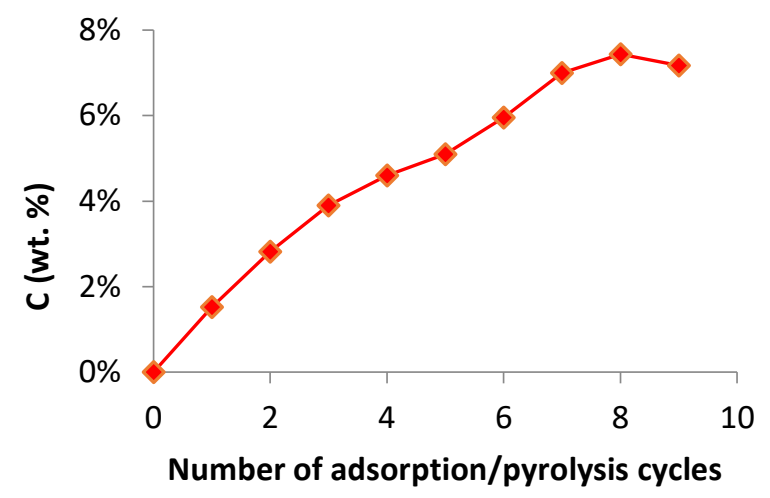

Figure 6 Carbon content of materials prepared by successive sorbitol adsorption/pyrolysis cycles

Both ${ }^{13} \mathrm{C}$ NMR and Raman spectroscopies showed that the carbon formed after 10 adsorption/pyrolysis cycles is semigraphitic, not functionalized with oxygen and most likely chemically inert. ${ }^{30}$ The NMR spectrum of the solid showed a single signal at $125 \mathrm{ppm}$ characteristic of aromatic carbons
(Figure 7-a). The G (graphitic) band of the Raman spectrum, which arises from the elongation vibration of $\mathrm{sp}_{2}$ carbons atoms and is located around $1580 \mathrm{~cm}^{-1}$ in pure graphitic carbon, is shifted to $1600 \mathrm{~cm}^{-1}$, indicating the presence of aromatics, polycyclic or/and olefinic species (Figure 7-b). The D (Default) band results from vibrations of defects in the graphitic structure (like $\mathrm{sp}_{3}$ carbon atoms). ${ }^{30}$ The intensity ratio of both bands (ID/IG) is often used to characterize the chemical structure of carbon materials: the highest the ratio, the less crystallized the carbon. In the case of carbon formed after 10 adsorption/pyrolysis cycles, a value of 0.68 was obtained, which clearly characterizes a semi-graphitic carbon. ${ }^{10,30}$
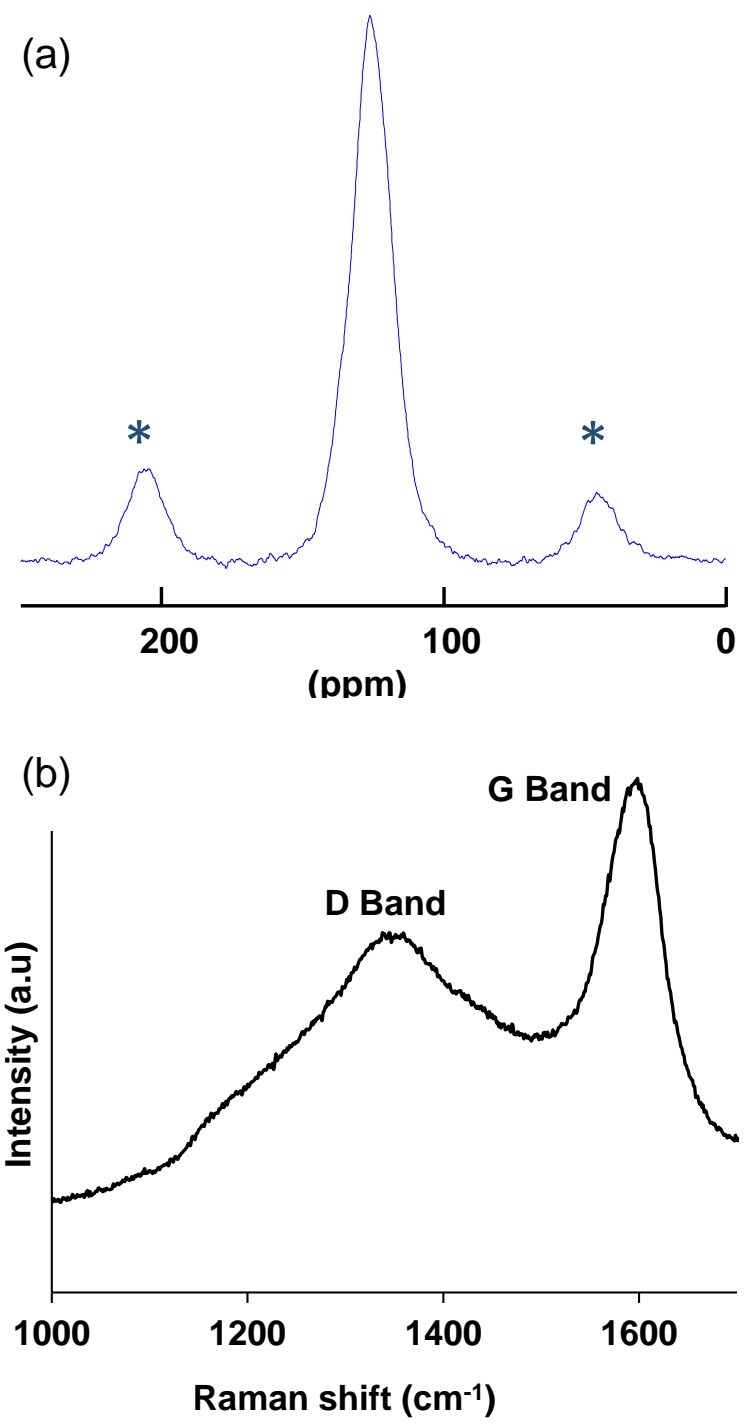

Figure $7{ }^{13} \mathrm{C}$ NMR (a) and Raman (b) spectra of a $\mathrm{C} / \gamma-\mathrm{Al}_{2} \mathrm{O}_{3}$ composite obtained after 10 adsorption/pyrolysis cycles. Asterisks in the NMR spectrum indicate spinning side-bands

This contrasts with data from Pham et al. who showed that the carbon formed from sucrose pyrolysis at $400^{\circ} \mathrm{C}$ is still highly functionalized with oxygen and remains reactive during a HT treatment at $200^{\circ} \mathrm{C}$ in liquid water. ${ }^{9}$ The average pore diameter, surface area and pore volume of composites prepared by sorbitol adsorption/pyrolysis at $600^{\circ} \mathrm{C}$ decreased with the carbon content and seemed to stabilize after 7 cycles (Table 1 
and Figure S10, ESI). After the HT treatment, the characteristics of the sample obtained after 7 cycles were not significantly modified (Table 1, cycle 7 data before HT are not available but we can assume that they are similar to the cycle 6 ones).

Table 1. Chemical composition and structural characteristics of $\mathrm{C} / \gamma$-alumina composites obtained by successive sorbitol adsorption/pyrolysis cycles

\begin{tabular}{|c|c|c|c|c|}
\hline Sample & $\begin{array}{c}\mathrm{S}_{\mathrm{BET}}^{\mathrm{a}} \\
\left(\mathrm{m}^{2} / \mathrm{g}\right)\end{array}$ & $\begin{array}{c}\mathrm{C} \\
(\text { wt. \%) }\end{array}$ & $\begin{array}{c}\text { Dp des. }^{\mathrm{a}} \\
(\mathrm{nm})\end{array}$ & $\begin{array}{c}\mathrm{Vp}^{\mathrm{a}} \\
(\mathrm{mL} / \mathrm{g})\end{array}$ \\
\hline$\gamma$-alumina & 212 & 0 & 9 & 0.55 \\
Cycle 1 & 207 & 1.5 & 7.9 & 0.48 \\
Cycle 4 & 180 & 4.6 & 6.7 & 0.35 \\
Cycle 6 & 185 & 5.9 & 6.4 & 0.33 \\
Cycle 7 HT & 198 & 6.9 & 6.5 & 0.32 \\
\hline
\end{tabular}

${ }^{\mathrm{a}} \mathrm{BET}$ surface area $\left(\mathrm{S}_{\mathrm{BET}}\right)$, pore diameter (Dp des, measured on the desorption branch of the isotherm) and pore volume ( $\mathrm{Vp}$ ) estimated from $\mathrm{N}_{2}$ adsorption/desorption isotherms

The small increase of the BET specific surface area could be attributed to the formation of $\mathrm{AlOOH}$ micro domains in agreement with Ravenelle et al. observations. ${ }^{5}$ The percentage of boehmite formed after HT treatment of $\mathrm{C} / \gamma$-alumina composites obtained by sorbitol adsorption/pyrolysis cycles decreased with the carbon content to a limit of 12-13\% after 7 cycles (Table 2, Figure 7 and Figure S11, ESI).

Table 2. Carbon content and percentage of boehmite formed after a hydrothermal treatment of $10 \mathrm{~h}$ at $200^{\circ} \mathrm{C}$ in water

\begin{tabular}{|c|c|c|}
\hline Sample & C (wt. \%) & AlOOH (wt. \%) \\
\hline Cycle 1 & $1.5 \%$ & $>95 \%$ \\
Cycle 2 & $2.8 \%$ & $>95 \%$ \\
Cycle 3 & $3.8 \%$ & $>95 \%$ \\
Cycle 4 & $4.6 \%$ & $61 \%$ \\
Cycle 5 & $5.1 \%$ & n.d. \\
Cycle 6 & $5.9 \%$ & $33 \%$ \\
Cycle 7 & $6.9 \%$ & $12 \%$ \\
Cycle 8 & $7.4 \%$ & $15 \%$ \\
Cycle 9 & $7.2 \%$ & $13 \%$ \\
\hline
\end{tabular}

${ }^{a}$ Estimated from XRD patterns of the treated solids using the calibration curve in Figure S1 (ESI)

Aqueous solutions recovered after treatments did not contain any trace of organic species, indicating that the stability of the solids was not due to sorbitol molecules desorbed in solution. Moreover, the instability could not be attributed to the fraction of free $\gamma$-alumina surface. Indeed, no correlation could be found between the amount of $\mathrm{AlOOH}$ formed and the free alumina surface, samples being very stable despite a high proportion of surface accessible to EtOH (Table 3). A solid prepared using a unique impregnation/pyrolysis step and hav- ing similar carbon content and free accessible surface gave 85 wt. $\%$ boehmite under the same conditions (Table 3 and Figure 7). This shows the importance of the multi-step process to obtain a material with a specific location of carbon species on the $\gamma$-alumina surface and thus a high HT stability.

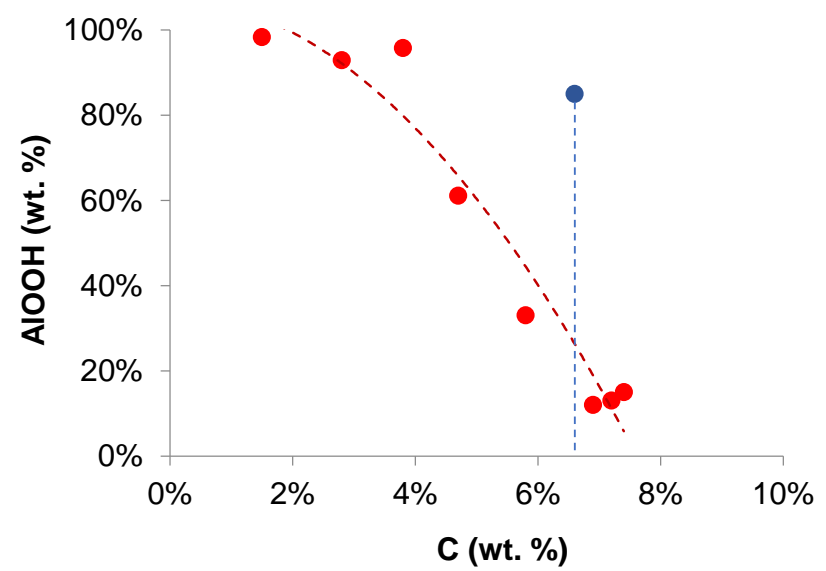

Figure 7 Fraction of $\mathrm{AlOOH}$ formed upon HT treatments as a function of the carbon content in compounds prepared by sorbitol adsorption/pyrolysis cycles and treated for $10 \mathrm{~h}$ at $200^{\circ} \mathrm{C}$ (red points). The blue point represents a sample containing 6.7 wt. $\% \mathrm{C}$ obtained by a single impregnation/pyrolysis step

Table 3. Free alumina surface determined by EtOH adsorption followed with TGA analysis

\begin{tabular}{|c|c|c|c|}
\hline Sample & $\begin{array}{c}\mathrm{C} \\
\text { (wt. \%) }\end{array}$ & $\begin{array}{c}\text { \% free } \\
\text { alumina } \\
\text { surface }^{\mathrm{a}}\end{array}$ & $\begin{array}{c}\text { AlOOH } \\
\text { after HT } \\
\text { treatment } \\
\text { (wt. \%) }^{\mathrm{b}}\end{array}$ \\
\hline $\begin{array}{c}\gamma \text {-alumina } \\
\begin{array}{c}\text { Sorbitol: 1 impregna- } \\
\text { tion/pyrolysis } \\
\text { Sorbitol: 7 cycles } \\
\text { adsorption/pyrolysis }\end{array}\end{array}$ & 6.7 & 100 & 100 \\
\hline
\end{tabular}

${ }^{a}$ Estimated by ethanol adsorption followed by TGA analysis

${ }^{b}$ Estimated from the corresponding XRD patterns using the calibration curve in Figure S1 (ESI)

Comparison of $\mathrm{C} / \gamma$-alumina composites obtained following different preparation methods.

Impregnation/pyrolysis of sucrose. $\mathrm{C} / \gamma$-alumina composites have been prepared by impregnation of sucrose solutions followed by pyrolysis. Two main synthesis parameters have been considered: the pyrolysis temperature that influences the chemical nature of the carbon deposit and the sucrose concentration that determines the final carbon content. Concerning the pyrolysis temperature, Pham et al. have reported that alumina could be protected under hydrothermal conditions by addition of $10 \mathrm{wt}$ \% carbon formed by pyrolysis of sucrose at $400^{\circ} \mathrm{C}$. At this temperature, the carbon phase formed remained highly oxygenated and functionalized. ${ }^{9}$ Other works related to the synthesis of carbon/alumina composites used higher pyrolysis temperatures but these studies were not devoted to the stability of materials in aqueous phase..$^{20,31,32}$ In the present 
study, two pyrolysis temperatures were applied: 400 and $600^{\circ} \mathrm{C}$

The second parameter concerns the amount of carbon formed at the surface of the alumina. In a first step, a minimal carbon content was determined considering a theoretical monolayer of graphite deposited on the entire surface of the alumina. This content was estimated to $0.16 \mathrm{~g}$ of carbon per gram of alumina (ie $14 \mathrm{wt}$ \% of the composite). This theoretical content represents an ideal case where carbon would be in graphitic form and homogeneously distributed over the entire surface of the alumina.

In a second step, another set of samples was prepared using twice the concentration to achieve a higher carbon content. Samples are denoted CA-X-Y where CA means carbon/alumina, $\mathrm{X}$ is the pyrolysis temperature (in ${ }^{\circ} \mathrm{C}$ ) and $\mathrm{Y}$ the carbon content after pyrolysis (in wt. \% of the composite). Their chemical and structural properties are listed in Table 4.

Table 4. Properties of C/alumina materials prepared using impregnation/pyrolysis of sucrose

\begin{tabular}{|c|c|c|c|c|c|}
\hline Sample & $\begin{array}{c}\mathrm{C} \\
(\% \mathrm{wt})^{\mathrm{a}}\end{array}$ & $\begin{array}{c}\mathrm{S}_{\mathrm{BET}}^{\mathrm{b}} \\
\left(\mathrm{m}^{2} / \mathrm{g}\right)\end{array}$ & $\begin{array}{c}\mathrm{Dp} \mathrm{Des}^{\mathrm{b}} \\
(\mathrm{nm})\end{array}$ & $\begin{array}{c}\mathrm{Vp}^{\mathrm{b}} \\
(\mathrm{mL} / \mathrm{g})\end{array}$ & $\begin{array}{c}\mathrm{Smic}^{\mathrm{b}} \\
\left(\mathrm{m}^{2} / \mathrm{g}\right)\end{array}$ \\
\hline$\gamma$-alumina & 0 & 212 & 8.8 & 0.55 & 9 \\
CA-400-11 & 11 & 203 & 7.9 & 0.36 & 0 \\
CA-400-19 & 19 & 205 & 7.9 & 0.25 & 33 \\
CA-600-9 & 9 & 194 & 8.5 & 0.4 & 21 \\
CA-600-15 & 15 & 240 & $\mathrm{x}$ & 0.34 & 47 \\
\hline
\end{tabular}

${ }^{\mathrm{a}}$ Determined with TGA analysis

${ }^{\mathrm{b}}$ Pore diameter (Dp), pore volume (Vp) and microporous surface area (Smic) determined from $\mathrm{N}_{2}$ sorption isotherms

For samples CA-400-11 and CA-600-9 prepared with a sucrose concentration equivalent to a theoretical graphite monolayer (14 wt. \%), the resulting carbon content is always lower than expected, suggesting that part of the impregnated carbon is released during the pyrolysis step, probably in the form of light hydrocarbons and/or $\mathrm{CO}_{2} / \mathrm{CO}$ mixtures. The same trend is observed for samples prepared with twice the amount of sucrose but the final carbon content is always above $14 \mathrm{wt}$ \% which indicates that the surface would be totally covered. For the two concentrations, the carbon content decreases with the pyrolysis temperature.

The surface area and pore diameter of $\mathrm{C} / \gamma$-alumina composites do not significantly differ from those of the original $\gamma$-alumina support (Table 4). In contrast, a significant decrease of the porous volume is observed for both pyrolysis temperatures. At low carbon contents, $\mathrm{N}_{2}$ adsorption/desorption isotherms are similar to those of $\gamma$-alumina and characteristic of mesoporous materials (Figure S12, ESI). For higher contents, a hysteresis loop with closure at $\mathrm{p} / \mathrm{p} 0=0.45$ is observed, indicating that large pores are partially blocked and accessible only via entrances smaller than $4 \mathrm{~nm} .^{33}$ The presence of an additional micro/mesoporosity (Table 4) suggests that the carbon formed upon pyrolysis is porous and partially blocks the large mesopores of $\gamma$-alumina. This is clearly evidenced by the almost complete disappearance of the original pore population at 8-9 $\mathrm{nm}$ in pore size distribution curves (Figure S12, ESI).
${ }^{13} \mathrm{C}$ solid-state NMR and Raman spectroscopies confirmed that carbon formed at $400^{\circ} \mathrm{C}$ still contained oxygenated species, resulting from an incomplete degradation of sucrose (Figures $\mathrm{S} 13$ and S14, ESI). In contrast samples prepared at $600^{\circ} \mathrm{C}$ showed all characteristics of semi-graphitic type carbon.

CVD of ethanol. Carbon/ $\gamma$-alumina composites are also very often prepared using a light gas phase precursor as a carbon source, for example ethanol. This precursor molecule has already been used in the literature to synthesize carbon/zeolite and carbon/titanium oxide composites, but not carbon on alumina to our knowledge. ${ }^{34,35}$ A series of five samples with a carbon content ranging from 2 to 29 wt. \% was prepared at $600^{\circ} \mathrm{C}$ by varying the reaction time $(1,2,4,6$ and 12 hours respectively). They are denoted CA-CVD-X, where CA stands for carbon/alumina, CVD refers to the preparation method and $\mathrm{X}$ is the carbon content in the composite (wt. \%) (Table 5).

Table 5. Carbon content and structural properties of $\mathrm{C} / \boldsymbol{\gamma}$ alumina composites prepared by CVD of ethanol

\begin{tabular}{|c|c|c|c|c|c|}
\hline Sample & $\begin{array}{c}\mathrm{C} \\
(\% \mathrm{wt})^{\mathrm{a}}\end{array}$ & $\begin{array}{c}\mathrm{S}_{\mathrm{BET}}^{\mathrm{b}} \\
\left(\mathrm{m}^{2} / \mathrm{g}\right)\end{array}$ & $\begin{array}{c}\mathrm{Dp} \mathrm{Des}^{\mathrm{b}} \\
(\mathrm{nm})\end{array}$ & $\begin{array}{c}\mathrm{Vp}^{\mathrm{b}} \\
(\mathrm{mL} / \mathrm{g})\end{array}$ & $\begin{array}{c}\mathrm{Smic}^{\mathrm{b}} \\
\left(\mathrm{m}^{2} / \mathrm{g}\right)\end{array}$ \\
\hline$\gamma$-alumina & 0 & 212 & 8.8 & 0.55 & 9 \\
CA-CVD-2 & $2 \%$ & 202 & 7.4 & 0.47 & 0 \\
CA-CVD-4 & $4 \%$ & 187 & 7.8 & 0.45 & 0 \\
CA-CVD-12 & $12 \%$ & 195 & 6.5 & 0.38 & 0 \\
CA-CVD-16 & $16 \%$ & 157 & 6.0 & 0.30 & 0 \\
CA-CVD-29 & $29 \%$ & 122 & - & 0.18 & 0 \\
\hline
\end{tabular}

${ }^{\mathrm{a}}$ Determined with TGA analysis

${ }^{\mathrm{b}}$ Pore diameter (Dp), pore volume (Vp) and micro/mesoporous surface area (Smic) determined from N2 sorption isotherms

The carbonization yield, which corresponds to the mass of carbon deposited compared to the quantity of vaporized ethanol (reduced to the mass of carbon contained in ethanol), is between 4 and $6 \%$ depending on the sample, indicating that the major part of ethanol present in the effluent gas does not react with alumina or does not lead to carbon formation. However, this synthesis route enables an easy control of the final carbon content in the materials since the mass or carbon formed is directly proportional to the duration of the reaction (Figure 8).

Both the specific surface area and pore volume significantly decrease with carbon content (Table 5). Changes become particularly important for the highest carbon content (CACVD-29) for which the specific surface area drops by $40 \%$ and the pore volume is decreased by a factor of 2.5 as compared to alumina. For this sample, the nitrogen desorption and average pore diameter distribution curves suggest a strong pore clogging with the appearance of the artifact at $3.5 \mathrm{~nm}$ already observed in samples prepared by sucrose pyrolysis but containing much less carbon (Figure S15, ESI). It is also noted that no microporosity was detected in these samples. 


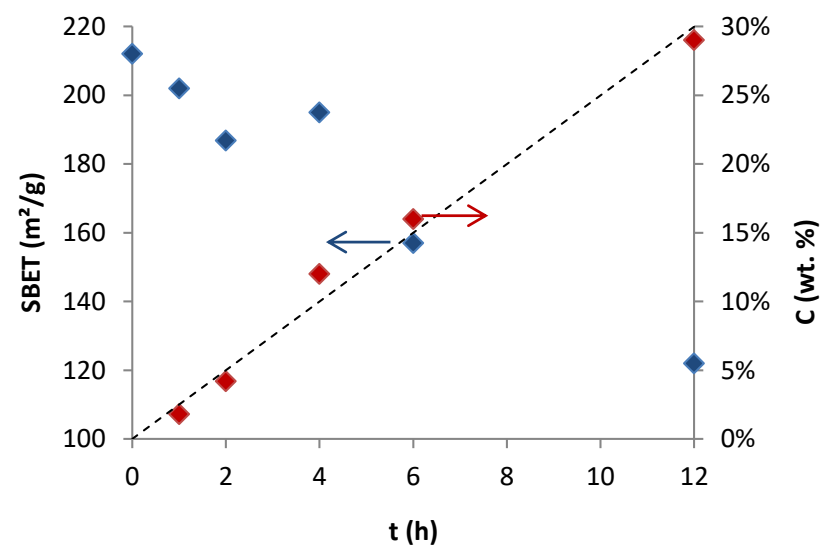

Figure 8 Carbon content and surface area of samples prepared by CVD as a function of reaction time.

The chemical nature of the carbon phase is quite similar to that obtained after pyrolysis of sucrose at $600^{\circ} \mathrm{C}$, the Raman spectrum of CA-CVD-29 being characteristic of a semi-graphitic carbon (Figure S16, ESI).

Composites prepared by CVD do not show any additional porosity, as it was the case for compounds obtained from sucrose pyrolysis. The carbon phase formed by CVD is therefore either non-porous or more uniformly deposited on the surface of the alumina, thus limiting the formation of carbonrich zones or aggregates. The second hypothesis is preferred because it is in agreement with the results of Ilinich et al. regarding C/alumina composites formed by ethylene carbonization. $^{36}$ The average pore diameter decreases much more rapidly with the carbon content than for samples prepared by impregnation/pyrolysis (Table 5 and Figures S12 and S15, ESI). This difference reinforces the hypothesis of a less homogeneous covering in the case of composites prepared by impregnation. Indeed, covering the pore surface with a regular carbon layer continuously decreases the pore diameter without pore blocking. In contrast, if porous carbon "clogs" the pores of alumina, the average pore diameter should remain practically unchanged with a sharp drop in intensity and a peak should appear at $3.5 \mathrm{~nm}$ in the pore size distribution curve, corresponding to the closure of the hysteresis at $\mathrm{p} / \mathrm{p} 0=0.45$.

Accessibility of the alumina surface determined by EtOH adsorption followed by ATG. Materials prepared by pyrolysis of sucrose at $600^{\circ} \mathrm{C}$ and those prepared by CVD at the same temperature show the same evolution of the free alumina surface with the carbon content (Figure 9). For samples prepared by CVD, the accessible alumina surface decreases from $80 \%$ at 4 wt. $\%$ carbon to $14 \%$ at 29 wt. \% carbon. For a content of $14 \mathrm{wt}$. \% corresponding to a theoretical graphite monolayer, only $50 \%$ of the surface of alumina is covered when carbon is prepared by impregnation/pyrolysis of sucrose whereas this value increases to ca. $75 \%$ when composites are prepared by CVD. The difference confirms that CVD promotes a more homogeneous carbon deposition than impregnation/pyrolysis, particularly at high carbon contents. However, these percentages of $\gamma$-alumina surface covered by carbon are very high compared to a material prepared by adsorption/pyrolysis of sorbitol. Indeed, even after 7 adsorption/pyrolysis cycles, only $23 \%$ of the surface was effectively protected by carbon (Table 3 ).

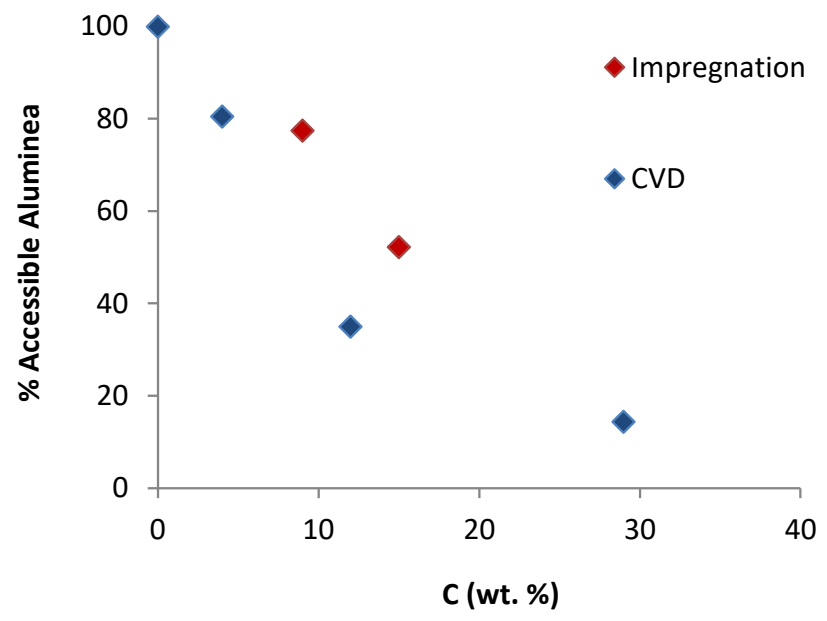

Figure 9 Fraction of accessible alumina surface as a function of the carbon mass content for samples prepared by impregnation/pyrolysis of sucrose and CVD

Stability of C/alumina composites. The protective effect of carbon formed by pyrolysis of sucrose at $600^{\circ} \mathrm{C}$ is quite low: despite a high carbon content (15 wt. \% C in CA-600-15), the solid contains $73 \%$ of boehmite after a HT treatment (Table 6 and Figure S20, ESI). Solids obtained at lower pyrolysis temperature $\left(400^{\circ} \mathrm{C}\right)$ seem to be more stable, with only $45 \%$ of boehmite formed in CA-400-11. However, the method does not enable a complete protection of alumina, contrasting with data reported by Pham et al. ${ }^{9}$ The main difference between samples prepared at 400 and $600{ }^{\circ} \mathrm{C}$ concerns the chemical nature of the carbon phase. When pyrolysis is carried out at $400^{\circ} \mathrm{C}$, the degradation of the sugar is incomplete and the carbon phase remains highly oxygenated and functionalized.

Table6. Fraction of free alumina surface and percentage of boehmite formed after HT treatment of various C/alumina composites. The evolution of the BET surface area upon HT treatment is also reported.

\begin{tabular}{|c|c|c|c|}
\hline Sample & $\begin{array}{c}\text { Free alumina } \\
\text { surface }^{\mathrm{a}} \\
(\%)^{\mathrm{a}}\end{array}$ & $\begin{array}{c}\% \text { AlOOH } \\
\text { after HT } \\
\text { treatment }^{\mathrm{b}}\end{array}$ & $\begin{array}{c}\text { Evolution } \mathrm{S}_{\mathrm{BET}} \\
\text { upon HT } \\
\text { treatment }^{\mathrm{c}, \mathrm{d}}\end{array}$ \\
\hline$\gamma$-alumina & 100 & 100 & $212 \rightarrow 44$ \\
CA-400-11 & & 28 & $203 \rightarrow 157$ \\
CA-400-19 & 77 & 95 & $205 \rightarrow 196$ \\
CA-600-9 & 52 & 73 & $194 \rightarrow 124$ \\
CA-600-15 & & $>95$ & $240 \rightarrow 253$ \\
CA-CVD-2 & 80 & $>90$ & n.d. \\
CA-CVD-4 & 34 & 68 & n.d. \\
CA-CVD-12 & & 52 & n.d. \\
CA-CVD-16 & 14 & 23 & n.d. \\
CA-CVD-29 & $122 \rightarrow 197$ \\
\hline
\end{tabular}

${ }^{a}$ Determined with EtOH adsorption followed by TGA analysis

${ }^{\mathrm{b}}$ Determined by XRD analysis after a hydrothermal treatment at $200^{\circ} \mathrm{C}$ for $10 \mathrm{~h}$ in water

${ }^{\mathrm{c}}$ Determined with $\mathrm{N}_{2}$ sorption isotherms analysis

${ }^{\mathrm{d}}$ Not determined 
Experimentally, liquid phases recovered after the HT test for samples pyrolyzed at $600^{\circ} \mathrm{C}$ are still clear, with a neutral or slightly basic $\mathrm{pH}$ value $(7<\mathrm{pH}<8)$. In contrast, solutions corresponding to solids pyrolyzed at $400^{\circ} \mathrm{C}$ are brownish and slightly acidic $(\mathrm{pH}=5.3$, Figure S19, ESI). The carbon phase is unstable under hydrothermal conditions and part of it decomposes in the aqueous phase, generating acidic organic oxygenated compounds in solution. In order to understand the influence of those compounds on the stability of $\gamma$-alumina, a sample was impregnated with sucrose $(0.41 \mathrm{~g}$ sucrose $/ \mathrm{g}$ of alumina; final carbon content $=14$ wt. $\%$ ), dried and directly tested without pyrolysis (see paragraph 2.5.1., ESI).

Results indicate that sucrose effectively prevents alumina transformation since only $12 \%$ of boehmite are formed under HT conditions, much less than for a sample with similar carbon content but pyrolyzed at $400^{\circ} \mathrm{C}(45 \%$ boehmite formed for CA-400-11, Table 6). Characterization of the solid and liquid phases after test confirm that oxygenated organic products resulting from the decomposition/polymerization of sucrose under HT conditions (5-HMF, levulinic acid, humins, acetic acid, etc.) can adsorb on the alumina surface and form a protective layer, as already observed for sorbitol.

Samples prepared by CVD also show a low hydrothermal stability. For example, $68 \%$ of CA-CVD 12 containing $12 \mathrm{wt}$. $\% \mathrm{C}$ are transformed into boehmite, which is far from the "total" protection expected for such a carbon content (Table 6 and Figure S21).

Nonetheless, the protective effect seems to be more pronounced for samples prepared by CVD than for samples prepared by impregnation of sucrose and pyrolyzed at $600^{\circ} \mathrm{C}$. Indeed, for an equivalent carbon content of about 15 wt. \%, the proportion of boehmite formed is $52 \%$ in the case of CVD whereas it is $73 \%$ in the case of impregnation/pyrolysis of sucrose at $600^{\circ} \mathrm{C}$ (Table 6). By extrapolation, the carbon content required to achieve total protection of alumina by CVD is estimated to be around $35 \mathrm{wt}$. \%. Such result is consistent with the observations of Xiong et al. who stabilized alumina with $35 \%$ wtcarbon deposited by CVD of methane. ${ }^{10}$ From a preparation point of view, the deposition of $35 \%$ of $\mathrm{C}$ would necessarily lead to significant changes in the textural properties of the starting alumina (clogging of pores, drastic reduction of surface area and pore volume, etc.) and is not an ideal solution.

The theoretical carbon content required for complete protection by CVD is therefore much greater than the value corresponding to a theoretical monolayer (14 wt. \%), which suggests either the formation of carbon clusters or a particular texture of our $\gamma$-alumina (surface roughness, platelet agglomeration...) not compatible with the calculation model based on a flat surface.

The stability of $\mathrm{C} / \gamma$-alumina composites obtained by the different methods are summarized in Figure 10. Whatever the preparation method, the amount of boehmite formed after a HT treatment decreases almost linearly with the carbon content in the composite. However, the amount of carbon necessary to ensure an almost complete protection of the support strongly depends on the preparation method. In particular, the synthesis route that consists in successive sorbitol impregnation/pyrolysis cycles enables a much better protection than any other conventional method: an almost complete protection is obtained with less than 8 wt. \% carbon. For comparison, only materials prepared by hydrothermal carbonization of sucrose show a similar protection, but with twice the amount of carbon. Those results unambiguously show that the stability of $\gamma$ alumina under hydrothermal conditions can be drastically improved by neutralizing only a small fraction of surface sites by carbon deposition. Non-selective methods, which randomly cover the surface with carbon are less effective and significantly modify the structural characteristics of the pristine alumina surface.

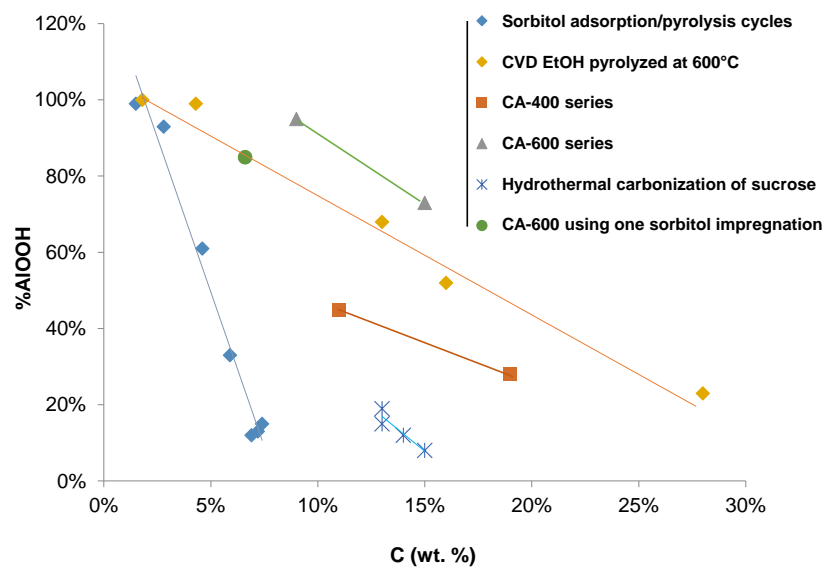

Figure 10 Percentage of boehmite formed after a hydrothermal treatment (water, $200^{\circ} \mathrm{C}, 10 \mathrm{~h}$ ) for $\mathrm{C} / \gamma$-alumina composites obtained following different methods

\section{- CONCLUSION}

Conventional methods of carbon deposition such as impregnation/pyrolysis or CVD can improve the stability of $\gamma$-alumina in hot liquid water. However, the amount of carbon necessary to prevent significant dissolution and formation of boehmite is sometimes so high that it totally modifies the porous structure and surface chemistry of the pristine crystals. We have shown that it is not necessary to cover entirely the surface of $\gamma$ alumina crystals with carbon to effectively reduce their dissolution in hot water. Crystals can be almost completely protected by neutralizing specific sites of the (110) basal planes. These sites, which were previously identified as neighboring octahedrally coordinated $\mathrm{Al}$ atoms in the vicinity of an $\mathrm{Al}$ tetrahedron are involved in the alumina dissolution. When sorbitol molecules are present in the hydrothermal solution, they adsorb selectively on the two Al octahedra and block the $\gamma$-alumina $\rightarrow$ boehmite transformation by preventing hydration of the third unsaturated $\mathrm{Al}$ site. This selective adsorption has been used to prepare carbon $/ \gamma$-alumina composites using sorbitol as carbon source. The method is not straightforward and it necessitates a succession of adsorption/pyrolysis cycles to neutralize progressively all sites potentially involved in the dissolution process. This new route allowed us to synthesize composites in which carbon was located exclusively on - or at least close to - hydration sites. Compared to carbon $/ \gamma$-alumina composites obtained by more conventional methods the amount of carbon necessary to stabilize the support is low, typically less than $8 \mathrm{wt}$. \%, which represents approx. $20 \%$ of the total surface of alumina crystals. As a consequence, most of the original surface remains accessible to molecules such as ethanol and solids retain textural and chemical properties of 
the original $\gamma$-alumina, even after a hydrothermal treatment in pure water. This is particularly important in the case where $\gamma$ alumina is used as support for metallic nanoparticles because the corresponding catalysts can be stable while preserving metal-support interactions. Even if the amount of carbon certainly depends on the morphology of the starting alumina, in particular the relative proportion of (110) faces in crystals, it is always small compared to a complete coverage. Clearly, the present method can hardly be applied at industrial scale because the multi-step preparation is long and necessitates a great number of adsorption/pyrolysis cycles. However, it is a proof of concept that paves the way to the preparation of hydrothermally stable catalyst supports with optimized surface composition and controlled properties.

\section{ASSOCIATED CONTENT}

Supporting Information. Determination of the boehmite content by XRD; determination of the carbon content in C/alumina composites by ATG; determination of the free alumina surface by ethanol adsorption followed by ATG; stability of pure $\gamma$-alumina in water studied by XRD and nitrogen adsorption; stability of $\gamma$ alumina in the presence of sorbitol studied by ${ }^{13} \mathrm{C} N M R$ and XRD; ${ }^{13} \mathrm{C}$ NMR spectra, Raman spectra and $\mathrm{N}_{2}$ adsorption/desorption isotherms of $\mathrm{C} / \gamma$-alumina composites obtained from sorbitol adsorption/pyrolysis cycles; characterization by nitrogen adsorption, ${ }^{13} \mathrm{C}$ NMR and Raman spectroscopy of solids prepared by impregnation/pyrolysis of sucrose; characterization by nitrogen adsorption and Raman spectroscopy of solids prepared by CVD of ethanol; hydrothermal stability of $\mathrm{C} / \gamma$-alumina composites obtained by different methods.

\section{AUTHOR INFORMATION}

\section{Corresponding Author}

* E-mail: alain.tuel@ ircelyon.univ-lyon1.fr (A.T.)

\section{ORCID}

Etienne Girel (E.G.): 0000-0001-6885-2275

Michèle Besson (M.B.): 0000-0003-0024-5676

Alain Tuel (A.T.): 0000-0001-7610-4074

\section{Author Contributions}

E.G. conducted the experimental work that was supervised by A.C., A.C., M.B. and A.T. All authors discussed the results. E.G. and A.T. wrote the manuscript that was revised and approved by all the authors.

\section{Notes}

The authors declare no competing financial interest

\section{REFERENCES}

(1) Fiorentino, G.; Ripa, M.; Ulgiati, S. Chemicals from Biomass: Technological versus Environmental Feasibility. A review. Biofuels, Bioprod. Bioref. 2017, 11, 195-214.

(2) Xiong, H.; Pham, H. N.; Datye, A. K. Hydrothermally Stable Heterogeneous Catalysts for Conversion of Biorenewables. Green Chem. 2014, 16, 4627-4643.

(3) Abi Aad, J.; Casale, S.; Michau, M.; Courty, P.; Diehl, F.; Marceau, E.; Carrier, X. Chemical Weathering of Alumina in Aqueous Suspension at Ambient Pressure: A Mechanistic Study. ChemCatChem 2017, 9, 2186-2194.

(4) Carrier, X.; Marceau, E.; Lambert, J.-F.; Che, M. Transformations of Gamma-alumina in Aqueous Suspensions 1. Alumina
Chemical Weathering studied as a function of $\mathrm{pH}$. J. Colloid Interface Sci. 2007, 308, 429-437.

(5) Ravenelle, R. M.; Copeland, J. R.; Kim, W.-G.; Crittenden, J. C.; Sievers, C. Structural Changes of $\gamma-\mathrm{Al}_{2} \mathrm{O}_{3}$ - Supported Catalysts in Hot Liquid Water. ACS Catal. 2011, 1, 552-561.

(6) Mironenko, R. M.; Belskaya, O. B.; Talsi, V. P.; Gulyaeva, T. I.; Kazakov, M. O.; Nizovskii, A. I.; Kalinkin, A. V.; Bukhtiyarov, V. I.; Lavrenov, A. V.; Likholobov, V. A. Effect of $\gamma$-Al2O3 Hydrothermal Treatment on the Formation and Properties of Platinum Sites in $\mathrm{Pt} / \gamma-\mathrm{Al}_{2} \mathrm{O}_{3}$ Catalysts. Appl. Catal. A 2014, 469, 472-482.

(7) Réocreux, R.; Jiang, T.; Iannuzzi, M.; Michel, C.; Sautet, P. Structuration and Dynamics of Interfacial Liquid Water at Hydrated $\gamma$-Alumina Determined by Ab Initio Molecular Simulations: Implications for Nanoparticle Stability. ACS Appl. Nano Mater. 2017, 1, 191199.

(8) Ngouana-Wakou, B. F.; Cornette, P.; Corral Valero, M.; Costa, D.; Raybaud, P. An Atomistic Description of the $\gamma$-Alumina/Water Interface revealed by Ab Initio Molecular Dynamics. J. Phys. Chem. C 2017, 121, 10351-10363.

(9) Pham, H. N.; Anderson, A. E.; Johnson, R. L.; Schmidt-Rohr, K.; Datye, A. K. Improved Hydrothermal Stability of Mesoporous Oxides for Reactions in the Aqueous Phase. Angew. Chem. Int. Ed. 2012, 51, 13163-13167.

(10) Xiong, H.; Schwartz, T. J.; Andersen, N. I.; Dumesic, J. A.; Datye, A. K. Graphitic-Carbon Layers on Oxides: Toward Stable Heterogeneous Catalysts for Biomass Conversion Reactions. Angew. Chem. Int. Ed. 2015, 54, 7939-7943.

(11) Abi Aad, J.; Courty, P.; Decottignies, D.; Michau, M.; Diehl, F.; Carrier, X.; Marceau, E. Inhibition by Inorganic Dopants of $\gamma$ Alumina Chemical Weathering under Hydrothermal Conditions: Identification of Reactive Sites and their Influence in Fischer-Tropsch Synthesis. ChemCatChem 2017, 9, 2106-2117.

(12) Liu, F.; Okolie, C.; Ravenelle, R. M.; Crittenden, J. C.; Sievers, C.; Bruijnincx, P. C.A.; Weckhuysen, B. M. Silica Deposition as an Approach for Improving the Hydrothermal Stability of an Alumina Support during Glycerol Aqueous Phase Reforming. Appl. Catal. A 2018, 551, 13-22.

(13) van Cleve, T.; Underhill, D.; Veiga Rodrigues, M.; Sievers, C.; Medlin, J. W. Enhanced Hydrothermal Stability of $\gamma-\mathrm{Al}_{2} \mathrm{O}_{3}$ Catalyst Supports with Alkyl Phosphonate Coatings. Langmuir 2018, 34, 3619-3625.

(14) Ravenelle, R. M.; Diallo, F. Z.; Crittenden, J. C.; Sievers, C. Effects of metal precursors on the stability and observed reactivity of $\mathrm{Pt} / \gamma-\mathrm{Al} 2 \mathrm{O} 3$ catalysts in aqueous phase reactions. ChemCatChem 2012, 4, 492-494.

(15) Ravenelle, R. M.; Copeland, J. R.; Van Pelt, Adam H.; Crittenden, J. C.; Sievers, C. Stability of Pt $/ \gamma-\mathrm{Al}_{2} \mathrm{O}_{3}$ Catalysts in Model Biomass Solutions. Top. Catal. 2012, 55, 162-174.

(16) Jongerius, A. L.; Copeland, J. R.; Foo, G. S.; Hofmann, J. P.; Bruijnincx, Pieter C. A.; Sievers, C.; Weckhuysen, B. M. Stability of $\mathrm{Pt} / \gamma-\mathrm{Al}_{2} \mathrm{O}_{3}$ Catalysts in Lignin and Lignin-Model Compound Solutions under Liquid Phase Reforming Reaction Conditions. ACS Catal. 2013, 3, 464-473.

(17) Copeland, J. R.; Santillan, I. A.; Schimming, S. M.; Ewbank, J. L.; Sievers, C. Surface Interactions of Glycerol with Acidic and Basic Metal Oxides. J. Phys. Chem. C 2013, 117, 21413-21425.

(18) Réocreux, R.; Girel, E.; Clabaut, P.; Tuel, A.; Besson, M.; Chaumonot, A.; Cabiac, A.; Sautet, P.; Michel, C. Reactivity of Shape-Controlled Crystals and Metadynamics Simulations Locate the Weak Spots of Alumina in Water Nat. Commun. 2019, 10, article number 3139.

(19) Lin, L.; Lin, W.; Zhu, Y. X.; Zhao, B. Y.; Xie, Y. C.; Jia, G. Q.; Li, C. Uniformly Carbon-Covered Alumina and its Surface Characteristics. Langmuir 2005, 21, 5040-5046.

(20) Caillot, M.; Chaumonnot, A.; Digne, M.; van Bokhoven, J. A. Quantification of Brønsted Acid Sites of Grafted Amorphous SilicaAlumina Compounds and their Turnover Frequency in $\mathrm{m}$-Xylene Isomerization. ChemCatChem 2013, 5, 3644-3656.

(21) Kwak, J. H.; Mei, D.; Peden, C. H. F.; Rousseau, R.; Szanyi, J. (100) facets of $\gamma$-Al2O3: The Active Surfaces for Alcohol Dehydration Reactions. Catal. Lett. 2011, 141, 649-655. 
(22) Ravenelle, R. M.; Schüßler, F.; D’Amico, A.; Danilina, N.; van Bokhoven, J. A.; Lercher, J. A.; Jones, C. W.; Sievers, C. Stability of Zeolites in Hot Liquid Water. J. Phys. Chem. C 2010, 114, 19582-19595.

(23) Jun-Cheng, L.; Lan, X.; Feng, X.; Zhan-Wen, W.; Fei, W. Effect of Hydrothermal Treatment on the Acidity Distribution of $\gamma$ $\mathrm{Al}_{2} \mathrm{O}_{3}$ Support. Appl. Surf. Sci. 2006, 253, 766-770.

(24) Lippens, B.C.; de Boer, J.H. Study of Phase Transformations During Calcination of Aluminum Hydroxides by Selected Area Electron Diffraction, Acta Cryst. 1964. 17, 1312-1321.

(25) Digne, M.; Sautet, P.; Raybaud, P.; Euzenc, P.; Toulhoat, H. Use of DFT to Achieve a Rational Understanding of Acid-Basic Properties of $\gamma$-Alumina Surfaces. J. Catal. 2004, 226, 54-68.

(26) Margulies, M. M.; Sixou, B.; David, L.; Vigier, G.; Dolmazon, R.; Albrand, M. Molecular Mobility of Sorbitol and Maltitol: A ${ }^{13} \mathrm{C}$ NMR and Molecular Dynamics Approach. Eur. Phys. J. E 2000, $3,55-62$.

(27) Rohrbaugh, R.H, Jurs P.C. Desciptions of Molecular Shape Applied in Studies of Structure/Activity and Structure/Property Relationships. Anal. Chim. Acta 1987, 199, 99-109.

(28) Copeland, J. R.; Shi, X.-R.; Sholl, D. S.; Sievers, C. Surface Interactions of $\mathrm{C}_{2}$ and $\mathrm{C}_{3}$ Polyols with $\gamma-\mathrm{Al}_{2} \mathrm{O}_{3}$ and the Role of Coadsorbed Water. Langmuir 2013, 29, 581-593.

(29) Watling, H. Gibbsite Crystallization Inhibition 2. Comparative Effects of Selected Alditols and Hydroxycarboxylic Acids. Hydrometallurgy 2000, 55, 289-309.
(30) Ferrari, A. C.; Robertson, J. Resonant Raman Spectroscopy of Disordered, Amorphous, and Diamond-like Carbon. Phys. Rev. B 2001, 64, Article number 075414

(31) Zheng, M.; Shu, Y.; Sun, J.; Zhang, T. Carbon-Covered Alumina: a Superior Support of Noble Metal-like Catalysts for Hydrazine Decomposition. Catal. Lett. 2008, 121, 90-96.

(32) He, S.; Sun, C.; Du, H.; Dai, X.; Wang, B. Effect of Carbon Addition on the Pt-Sn $/ \gamma-\mathrm{Al}_{2} \mathrm{O}_{3}$ Catalyst for Long Chain Paraffin Dehydrogenation to Olefin. Chem. Eng. J. 2008, 141, 284-289.

(3330) Groen, J.C.; Pérez-Ramirez, J. Critical Appraisal of Mesopore Characterization by Adsorption Analysis. Appl. Catal. A 2004, $268,121-125$

(34) Kim, K.; Choi, M.; Ryoo, R. Ethanol-Based Synthesis of Hierarchically Porous Carbon using Nanocrystalline Beta Zeolite Template for High-Rate Electrical Double Layer Capacitor. Carbon 2013 , $60,175-185$.

(35) Janus, M.; Inagaki, M.; Tryba, B.; Toyoda, M.; Morawski, A. W. Carbon-Modified $\mathrm{TiO}_{2}$ Photocatalyst by Ethanol Carbonisation. Appl. Catal. B: 2006, 63, 272-276.

(36) Ilinich, G. N.; Kvon, R. I.; Ayupov, A. B.; Chumachenko, V. A.; Romanenko, A. V. Mesoporous Alumina Infiltrated with a very thin and complete Carbon Layer. Microporous Mesoporous Mater. 2015, 208, 120-128. 


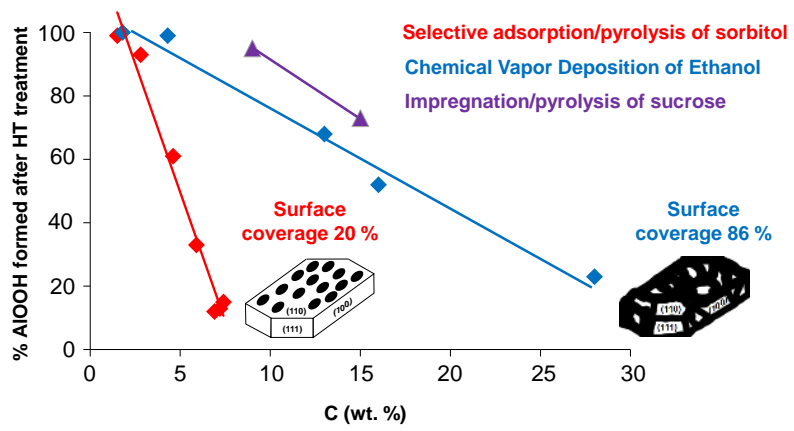

